\title{
A Micelle Fusion-Aggregation Assembly Approach to Mesoporous Carbon Materials with Rich Active Sites for Ultra-Sensitive Ammonia Sensing
}

Wei Luo, ${ }^{\dagger} \ddagger$ Tao Zhao, ${ }^{\dagger}$ Yuhui Li, ${ }^{\ddagger}$ Jing Wei, ${ }^{\ddagger}$ Pengcheng $\mathrm{Xu}, \S$ Xinxin $\mathrm{Li}, \S$ Youwei Wang, ${ }^{\perp}$ Wenqing Zhang, ${ }^{\perp}, \nabla$ Ahmed A. Elzatahry, ${ }^{\#}$ Abdulaziz Alghamdi, ${ }^{\xi}$

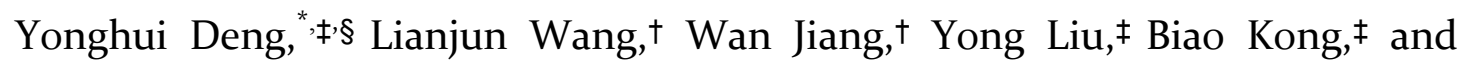
Dongyuan Zhao";

† State Key Laboratory for Modification of Chemical Fibers and Polymer Materials, College of Materials Science and Engineering, Donghua University, Shanghai 201620, P. R. China.

₹ Department of Chemistry, Laboratory of Advanced Materials, State Key Laboratory of Molecular Engineering of Polymers, Shanghai Key Laboratory of Molecular Catalysis and Innovative Materials, Collaborative Innovation Center of Chemistry for Energy Materials (iChEM), Fudan University, Shanghai 200433, P. R. China.

${ }^{\S}$ State Key Lab of Transducer Technology, Shanghai Institute of Microsystem and Information Technology, Chinese Academy of Sciences, Shanghai 20005o, P. R. China.

${ }^{\perp}$ State Key Laboratory of High Performance Ceramics and Superfine Microstructures, Shanghai Institute of Ceramics, Chinese Academy of Sciences, Shanghai 20005o, P. R. China.

${ }^{\nabla}$ Materials Genome Institute, Shanghai University, Shanghai 200444, P. R. China.

\# Materials Science and Technology Program, College of Arts and Sciences, Qatar University, PO Box 2713, Doha, Qatar.

${ }^{\xi}$ Department of Chemistry, College of Science, King Saud University, Riyadh 11451, Saudi Arabia. 


\section{Supplementary Experimentals}

Chemicals. Tetraethylorthosilicate (TEOS), concentrated hydrochloric acid solution (37 wt \%), ethanol, tetrahydrofuran (THF), phenol, resorcinol, and formaldehyde aqueous solution (37 wt \%), were AR grade and purchased from Sino-Pharm Chemical Reagent Co. Ltd. Pluronic block copolymers poly (propylene oxide)-block-poly (ethylene oxide)-block-poly (propylene oxide) (F127, Mw: 12600 $\mathrm{g} / \mathrm{mol}, \mathrm{EO}_{106} \mathrm{PO}_{70} \mathrm{EO}_{106}$ ) were purchased from Aldrich.

\section{Synthesis of Ordered Mesoporous Carbon-Silica Composites with 2-D Hexagonal}

Mesoporous Structure and Large Buckled Mesopores. The synthesis was similar to that of the sample Carbon- $\mathrm{PEO}_{117}-b-\mathrm{PS}_{198}$, except that hydrochloride solution was used as the catalysis instead of ammonia water. Typically, $0.45 \mathrm{~g}$ of amphiphilic diblock copolymer $\mathrm{PEO}_{117}-b-\mathrm{PS}_{198}$ was dissolved in $12 \mathrm{~mL}$ of THF to form a clear solution in a glass vial. $0.1 \mathrm{~g}$ of resorcinol and $1.5 \mathrm{~g}$ of $\mathrm{HCl}$ solution $(0.4 \mathrm{M})$ were added in to the solution, and the resultant clear solution was allowed to evaporate THF in a hood in air under magnetic stirring (ca. $100 \mathrm{rpm})$. After stirring for $3 \mathrm{~h}, 0.14$ $\mathrm{mL}$ of formaldehyde aqueous solution (37 wt.\%) was added under continuous stirring. After $2 \mathrm{~h}, 0.10 \mathrm{ml}$ of TEOS was added under stirring. As the reaction proceeds with the evaporation of THF, reddish precipitate was formed at the bottom of the remaining solution. After evaporation for $30 \mathrm{~h}$, the precipitate was collected by centrifugation, washed with deionized water for five times, and dried at $60{ }^{\circ} \mathrm{C}$ for $12 \mathrm{~h}$. To remove the copolymer templates, the as-made composites were calcined at $600{ }^{\circ} \mathrm{C}$ with a ramp of $1{ }^{\circ} \mathrm{C} \min ^{-1}$ and held for $3 \mathrm{~h}$ in $\mathrm{N}_{2}$, and thus ordered mesoporous carbon-silica composites were obtained.

\section{Synthesis of Ordered Mesoporous Silica with 2-D Hexagonal Mesoporous}

Structure and Large Buckled Mesopores. The synthesis was similar to that for that ordered mesoporous carbon-silica composites except that only TEOS was used as the precursor. In a typical synthesis, $0.45 \mathrm{~g}$ of amphiphilic diblock copolymer $\mathrm{PEO}_{117}-b-\mathrm{PS}_{198}$ and $1.5 \mathrm{~g}$ of $\mathrm{HCl}$ solution $(0.4 \mathrm{M})$ was dissolved in $12 \mathrm{~mL}$ of THF. 
The obtained solution was allowed to evaporate THF in a hood in air under magnetic stirring (ca. $100 \mathrm{rpm}$ ). After stirring for $3 \mathrm{~h}, 0.36 \mathrm{~mL}$ of TEOS was added under stirring. As the reaction proceeds with the evaporation of THF during stirring, white precipitate was formed at the bottom of the remaining solution. After evaporation for $30 \mathrm{~h}$, the precipitate was collected by centrifugation, washed with deionized water for five times, and dried at $60{ }^{\circ} \mathrm{C}$ for $12 \mathrm{~h}$. The dried product was calcined in air at $550{ }^{\circ} \mathrm{C}$ for $5 \mathrm{~h}$, resulting in the ordered mesoporous silica with large buckled mesopores.

Synthesis of C-FDU-15. The conventional mesoporous carbon C-FDU-15 was synthesized as follows: Pluronic F127 (1.00 g) was dissolved in ethanol (20.0 g), then the ethanol solution of the resol precursor containing phenol $(0.61 \mathrm{~g}, 6.50 \mathrm{mmol})$ and $(0.39 \mathrm{~g}, 13.0 \mathrm{mmol})$ formaldehyde was added with stirring within $10 \mathrm{~min}$ to form a homogeneous solution with the molar composition of F127/phenol/formaldehyde/ ethanol of $0.012: 1: 2: 67$. The solution was transferred to a dish and the ethanol evaporated at room temperature over $5-8 \mathrm{~h}$ to produce a transparent membrane. The membrane was then heated in an oven at $100{ }^{\circ} \mathrm{C}$ for $24 \mathrm{~h}$ to thermopolymerize the phenolic resins. The products were pyrolyzed at $350{ }^{\circ} \mathrm{C}$ under nitrogen for $5 \mathrm{~h}$ to selectively decompose Pluronic F127 template, and to be further carbonized under nitrogen at $600{ }^{\circ} \mathrm{C}$ for $5 \mathrm{~h}$. 
Table S1. Textural properties of the mesoporous carbons synthesized by using PEO- $b$-PS block copolymers as templates via the micelle fusion-aggregation assembly method.

\begin{tabular}{|c|c|c|c|c|c|}
\hline Sample & $\begin{array}{l}\text { Unit } \\
\text { cell size } \\
(\mathrm{nm})\end{array}$ & $\begin{array}{l}\text { Pore } \\
\text { size } \\
(\mathrm{nm})\end{array}$ & $\begin{array}{l}\text { Pore wall } \\
\text { thickness } \\
\quad(\mathrm{nm})\end{array}$ & $\begin{array}{c}\text { Pore } \\
\text { volume } \\
\left(\mathrm{cm}^{3} \mathrm{~g}^{-1}\right)\end{array}$ & $\begin{array}{c}\text { BET } \\
\text { surface } \\
\text { area } \\
\left(\mathrm{m}^{2} \mathrm{~g}^{-1}\right)\end{array}$ \\
\hline $\begin{array}{c}\text { carbon- } \mathrm{PEO}_{117} \\
-b-\mathrm{PS}_{198}\end{array}$ & 28.3 & 26.2 & 2.1 & 0.49 & 555 \\
\hline $\begin{array}{c}\text { carbon- } \mathrm{PEO}_{117} \\
-b-\mathrm{PS}_{264}\end{array}$ & 39.2 & 36.3 & 2.9 & 0.54 & 571 \\
\hline $\begin{array}{c}\text { carbon- } \mathrm{PEO}_{117} \\
-b-\mathrm{PS}_{89}\end{array}$ & - & 10.9 & - & 0.59 & 880 \\
\hline
\end{tabular}




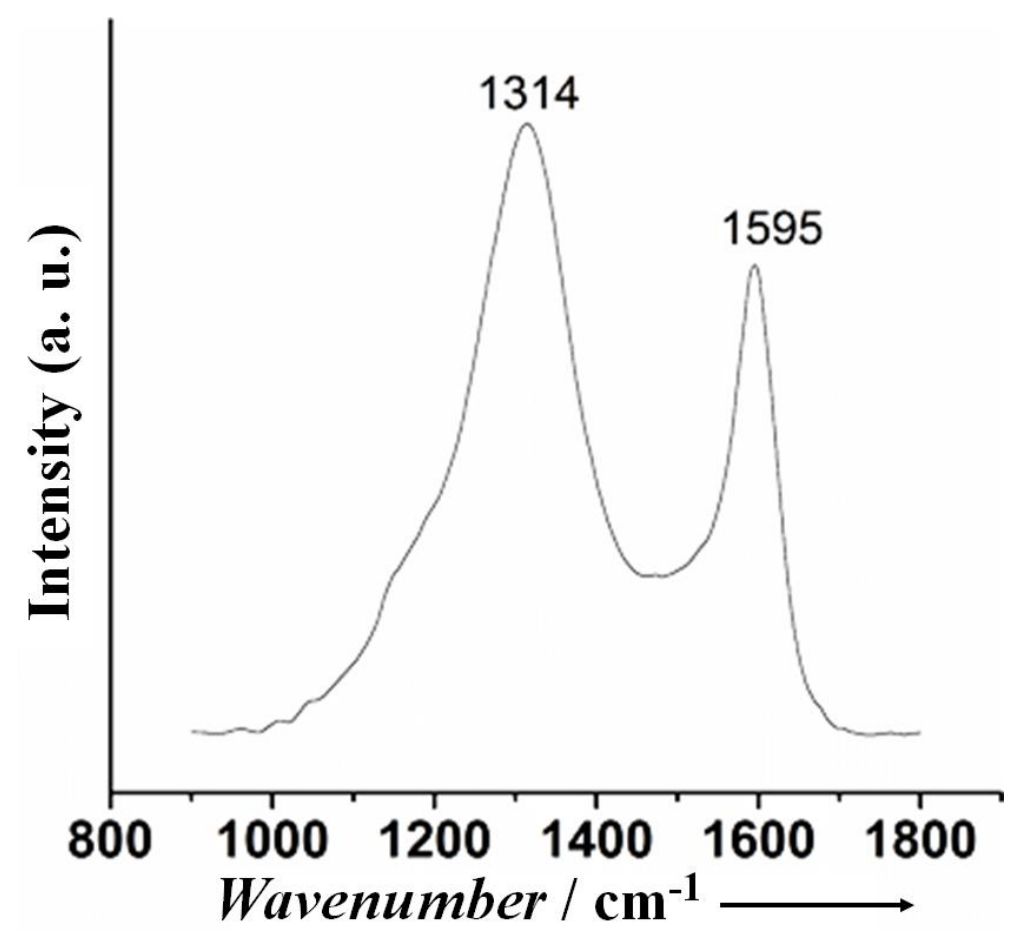

Figure S1. The Raman spectrum of the mesoporous carbon carbon- $\mathrm{PEO}_{117}-b-\mathrm{PS}_{198}$ synthesized by the micelle fusion-aggregation assembly method after pyrolysis at 600 ${ }^{\circ} \mathrm{C}$. 


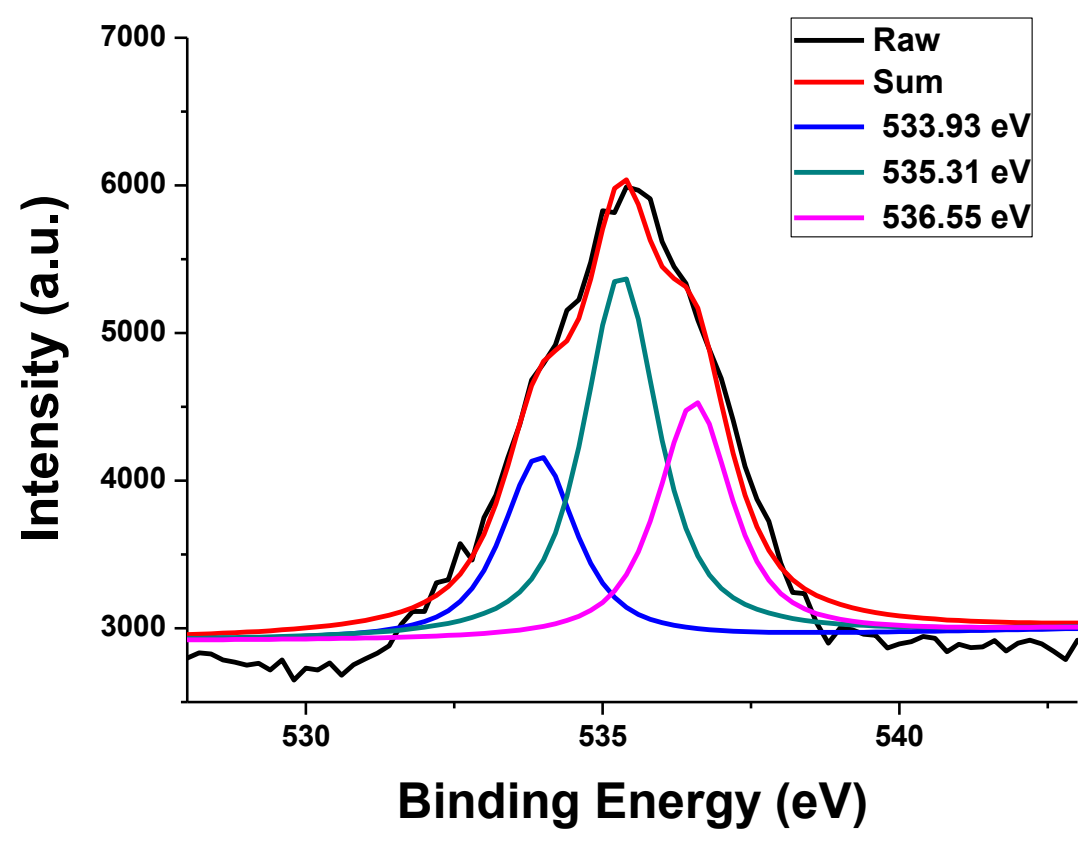

Figure S2. XPS spectra of the mesoporous carbon carbon- $\mathrm{PEO}_{117}-b-\mathrm{PS}_{198}$ synthesized by the micelle fusion-aggregation assembly method after pyrolysis at $600{ }^{\circ} \mathrm{C}$. 


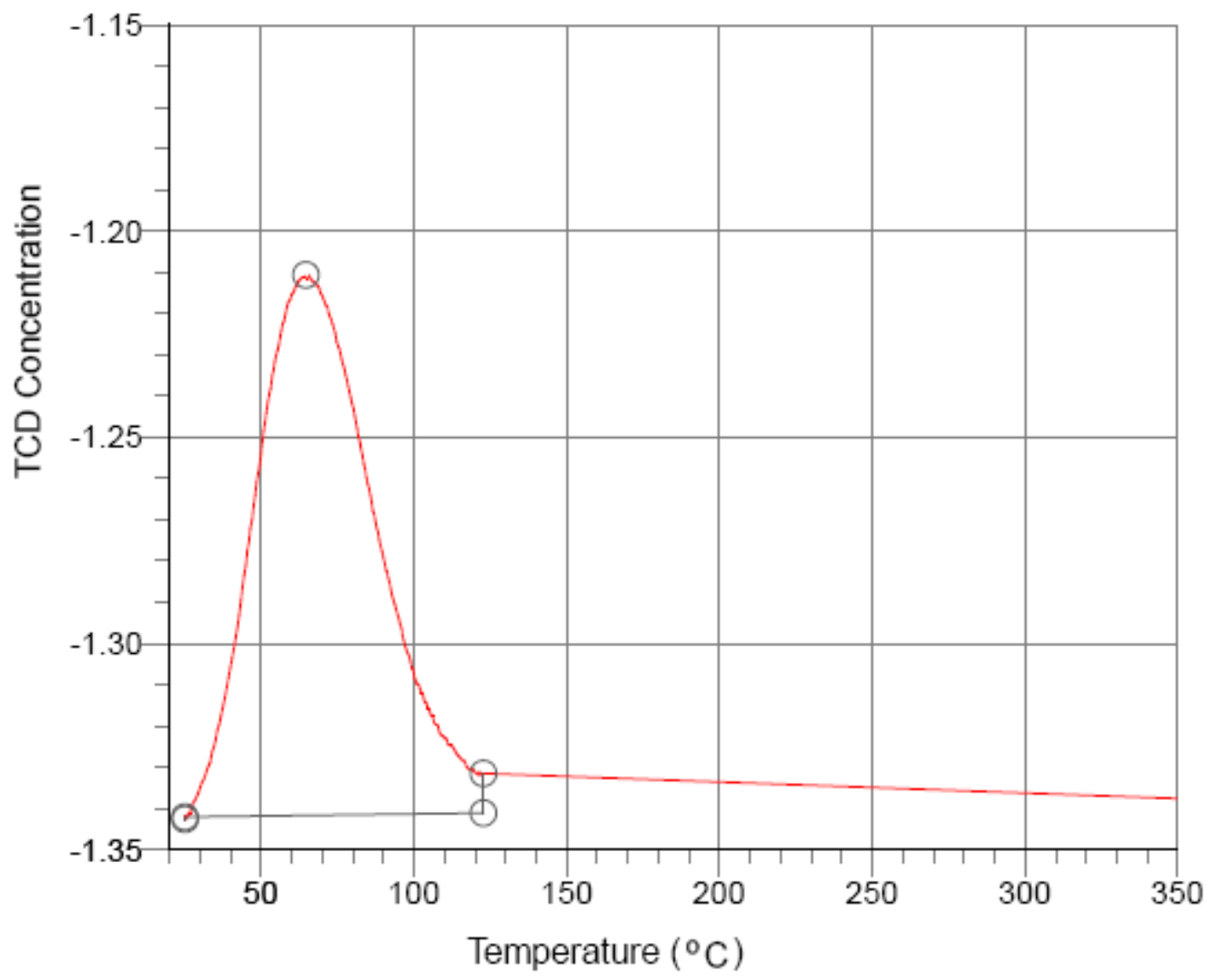

Figure S3. The $\mathrm{NH}_{3}-\mathrm{TPD}$ profile of the mesoporous carbon carbon- $\mathrm{PEO}_{117}-b-\mathrm{PS}_{198}$ measured in the temperature range of $25-350{ }^{\circ} \mathrm{C}$. 

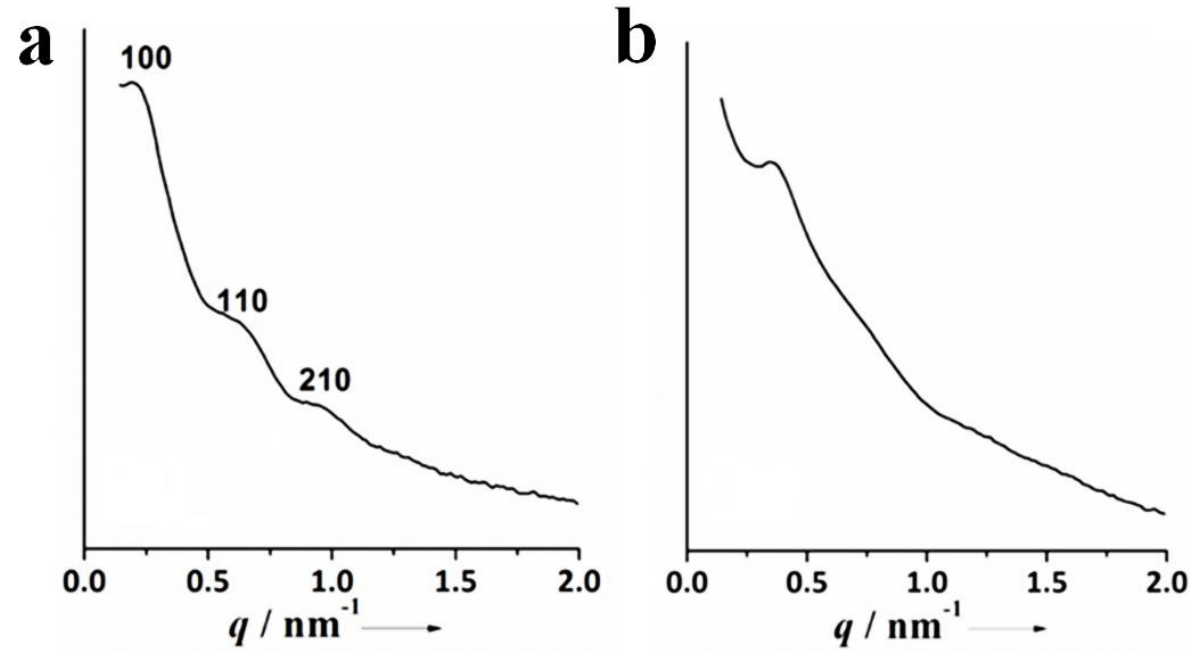

Figure S4. SAXS patterns of the ordered mesoporous carbon products: (a) carbon- $\mathrm{PEO}_{117}-b-\mathrm{PS}_{264}$ and (b) carbon- $\mathrm{PEO}_{117}-b-\mathrm{PS}_{89}$ synthesized by the micelle fusion-aggregation assembly method after pyrolysis at $600{ }^{\circ} \mathrm{C}$, using $\mathrm{PEO}_{117}-b-\mathrm{PS}_{264}$ and $\mathrm{PEO}_{117}-b-\mathrm{PS}_{89}$ as the template, respectively. 

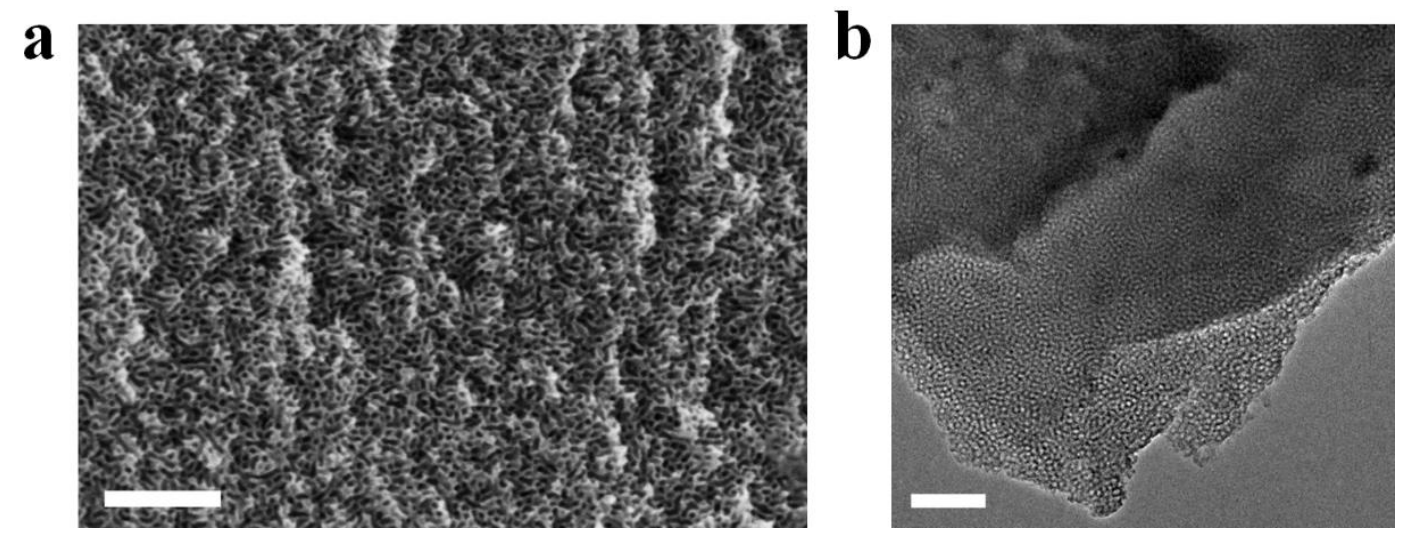

Figure S5. The FESEM image (a) and TEM image (b) of the mesoporous carbon carbon- $\mathrm{PEO}_{117}-b-\mathrm{PS}_{89}$ synthesized via the micelle fusion-aggregation assembly method after pyrolysis at $600{ }^{\circ} \mathrm{C}$ using $\mathrm{PEO}_{117}-b-\mathrm{PS}_{89}$ as the template. Scale bars is $200 \mathrm{~nm}$. 

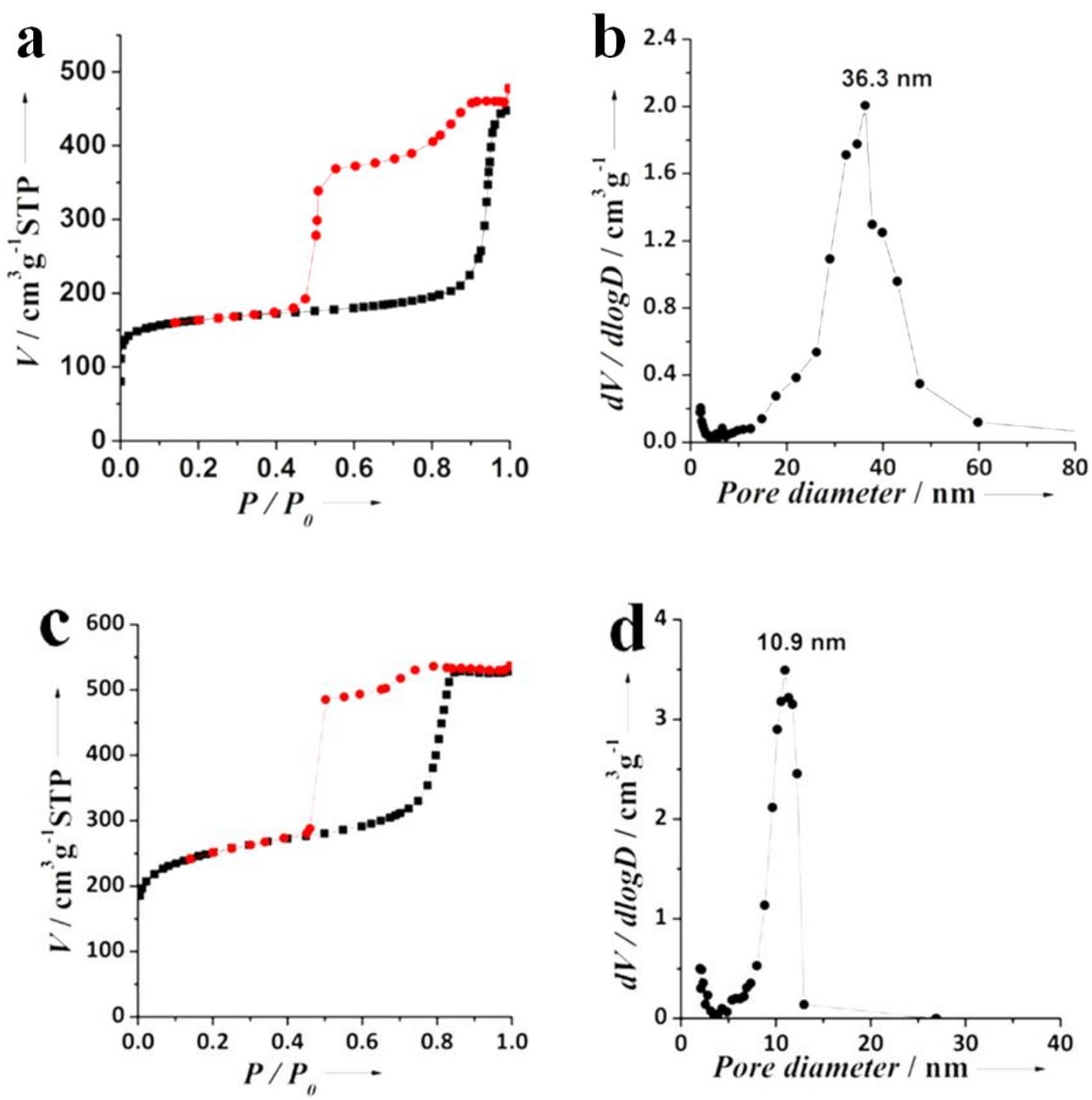

Figure S6. $\mathrm{N}_{2}$ adsorption-desorption isotherms (a, c) and the pore size distribution curve $(b, d)$ of the mesoporous carbon carbon- $\mathrm{PEO}_{117}-b-\mathrm{PS}_{264}(\mathrm{a}, \mathrm{b})$ and carbon- $\mathrm{PEO}_{117}-b-\mathrm{PS}_{89}(\mathrm{c}, \mathrm{d})$ synthesized via the micelle fusion-aggregation assembly method after pyrolysis at $600{ }^{\circ} \mathrm{C}$ using $\mathrm{PEO}_{117}-b-\mathrm{PS}_{264}$ and $\mathrm{PEO}_{117}-b$ - $\mathrm{PS}_{89}$ as the template, respectively. 

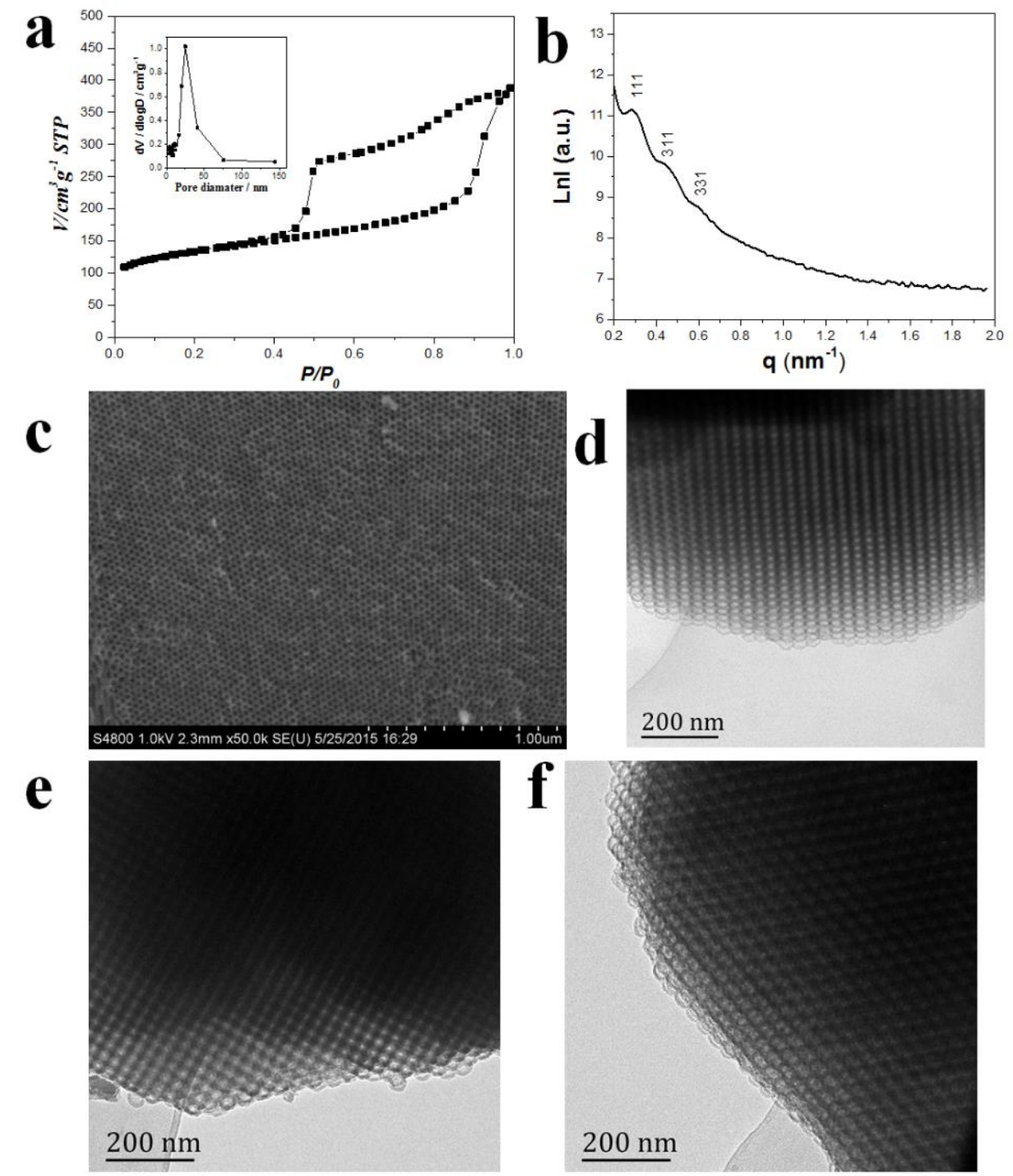

Figure S7. $\mathrm{N}_{2}$ adsorption-desorption isotherms (a) and the pore size distribution curve (inset in a) of the mesoporous carbon carbon- $\mathrm{PEO}_{117}-b$ - $\mathrm{PS}_{198}$-static prepared by the same approach and condition with that for the sample carbon- $\mathrm{PEO}_{117}-b-\mathrm{PS}_{198}$ but without stirring. The SAXS pattern (b), FESEM image (c) and TEM images taken along the (d) [100], (e) [110], (f) [211] of carbon- $-\mathrm{PEO}_{117}-b-\mathrm{PS}_{198}$-static. 

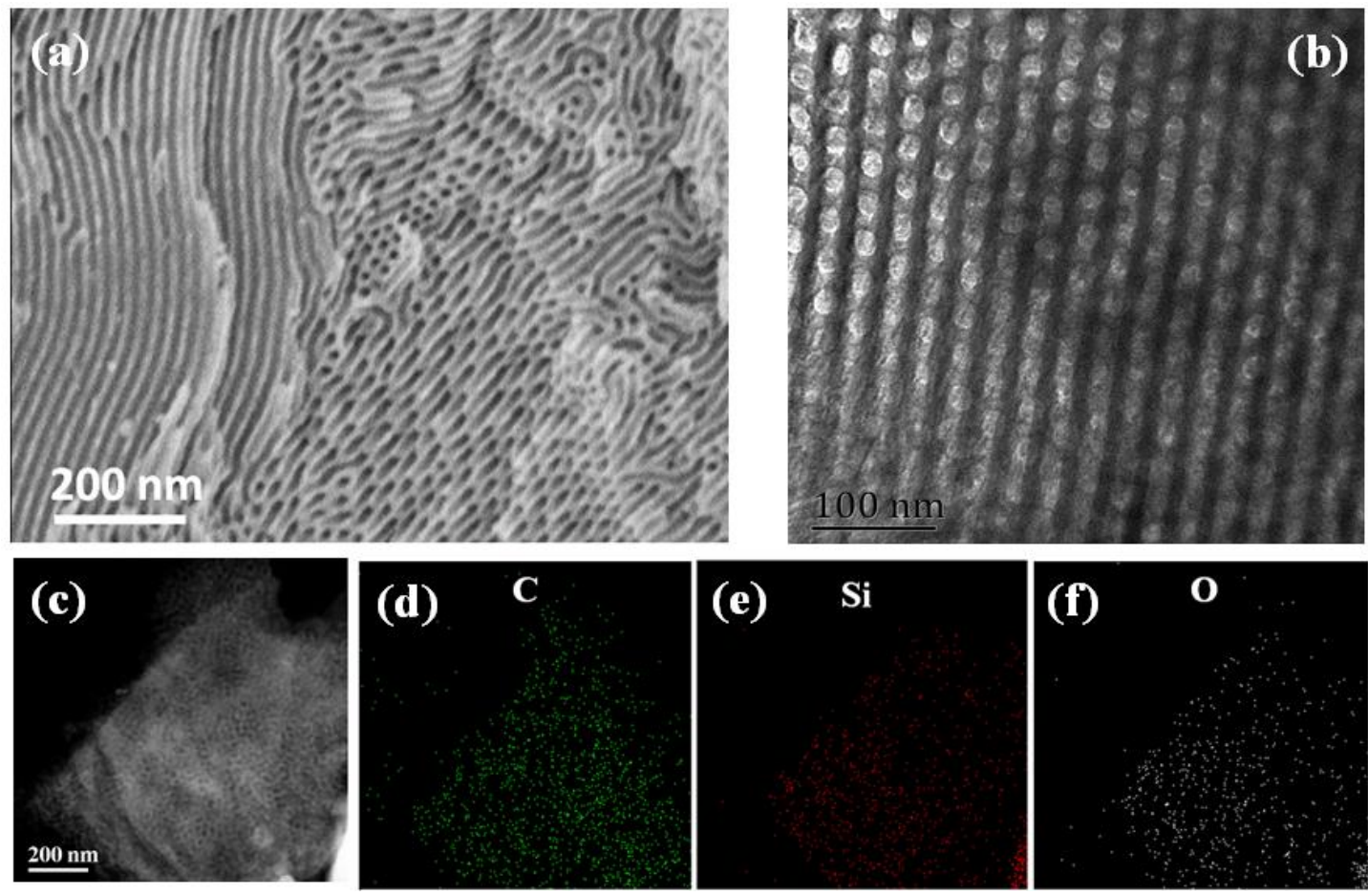

Figure S8. SEM (a), TEM (b) and (c) scanning transmission electron microscopy (STEM) images of the ordered mesoporous carbon-silica composites templated from $\mathrm{PEO}_{117}-b-\mathrm{PS}_{198}$ after pyrolysis at $600{ }^{\circ} \mathrm{C}$. Panels (d-f) show the elemental mapping results of the composites (d: carbon, e: silicon, f: oxygen), indicating that silica species were highly dispersed in the carbon matrix. 

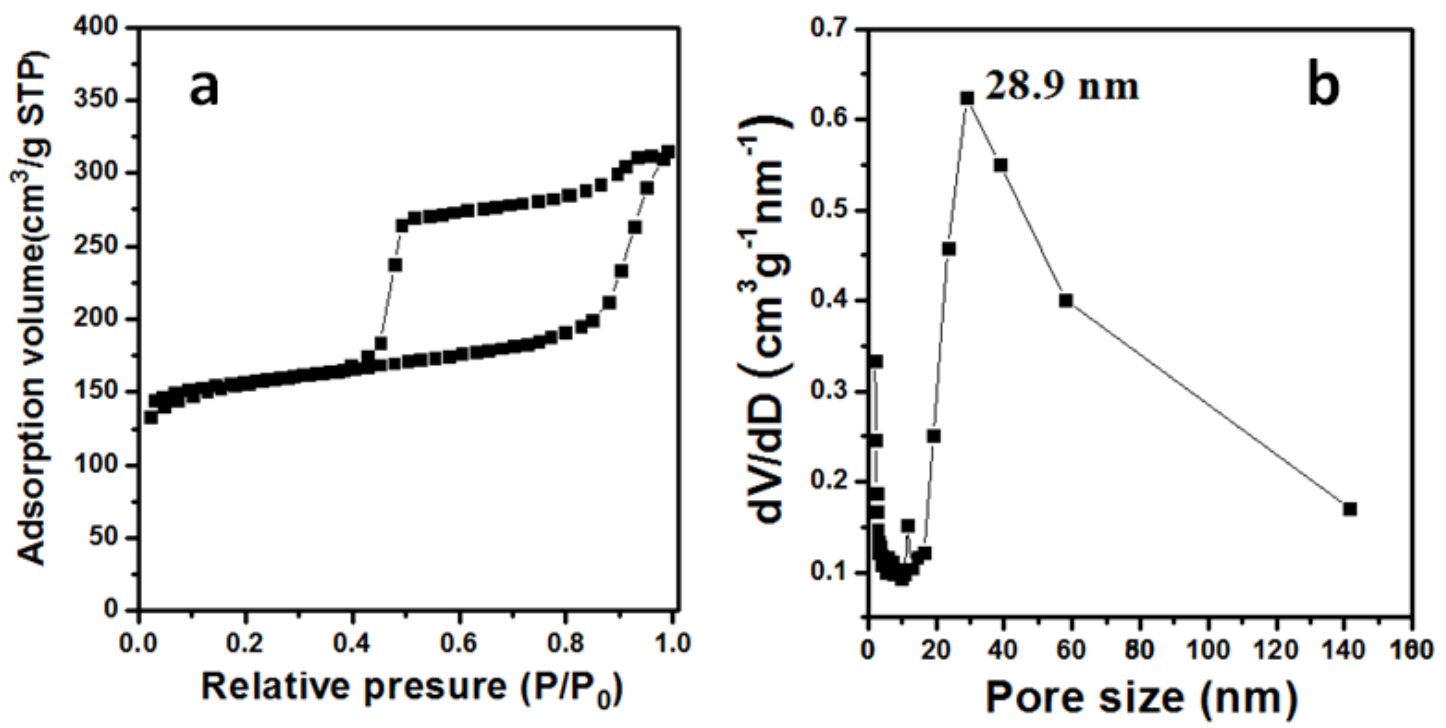

Figure S9. $\mathrm{N}_{2}$ adsorption-desorption isotherms (a) and the pore size distribution curve (d) of the ordered mesoporous carbon-silica composites templated from $\mathrm{PEO}_{117}-b-\mathrm{PS}_{198}$ by the solvent evaporation induced micelle fusion-aggregation assembly method. 

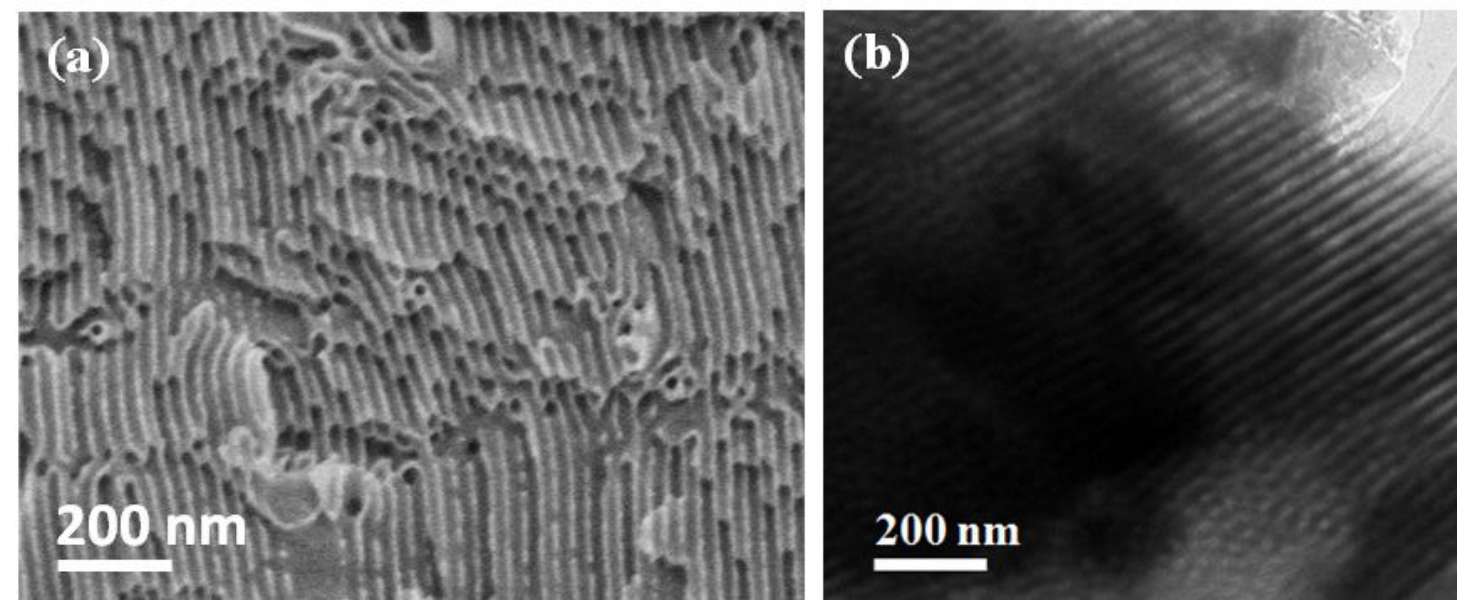

Figure S10. (a) SEM and (b) TEM images of the ordered mesoporous silica templated from $\mathrm{PEO}_{117}-b-\mathrm{PS}_{198}$ by the solvent evaporation induced micelle fusion-aggregation assembly method. 

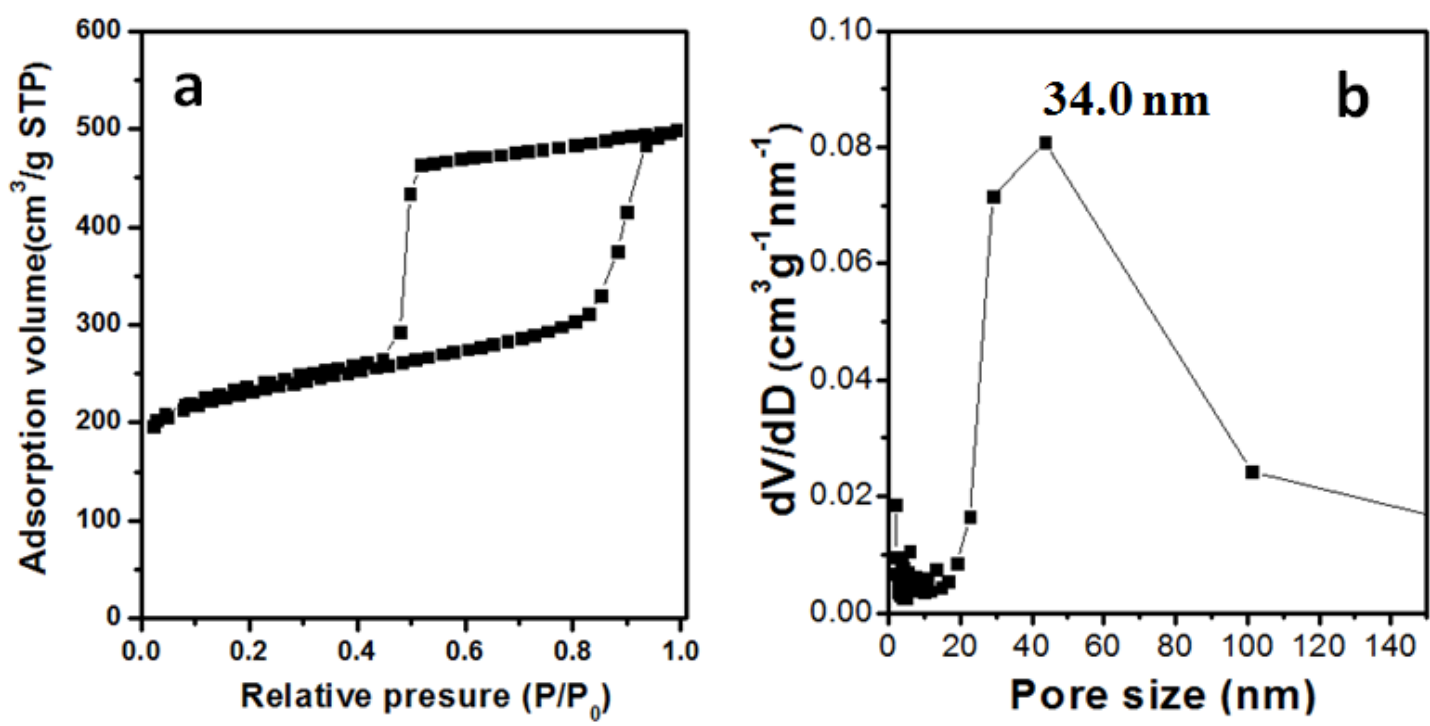

Figure S11. (a) $\mathrm{N}_{2}$ adsorption-desorption isotherms and (b) the pore size distribution curves of the ordered mesoporous silica templated from $\mathrm{PEO}_{117}-b-\mathrm{PS}_{198}$ by the solvent evaporation induced micelle fusion-aggregation assembly method. 


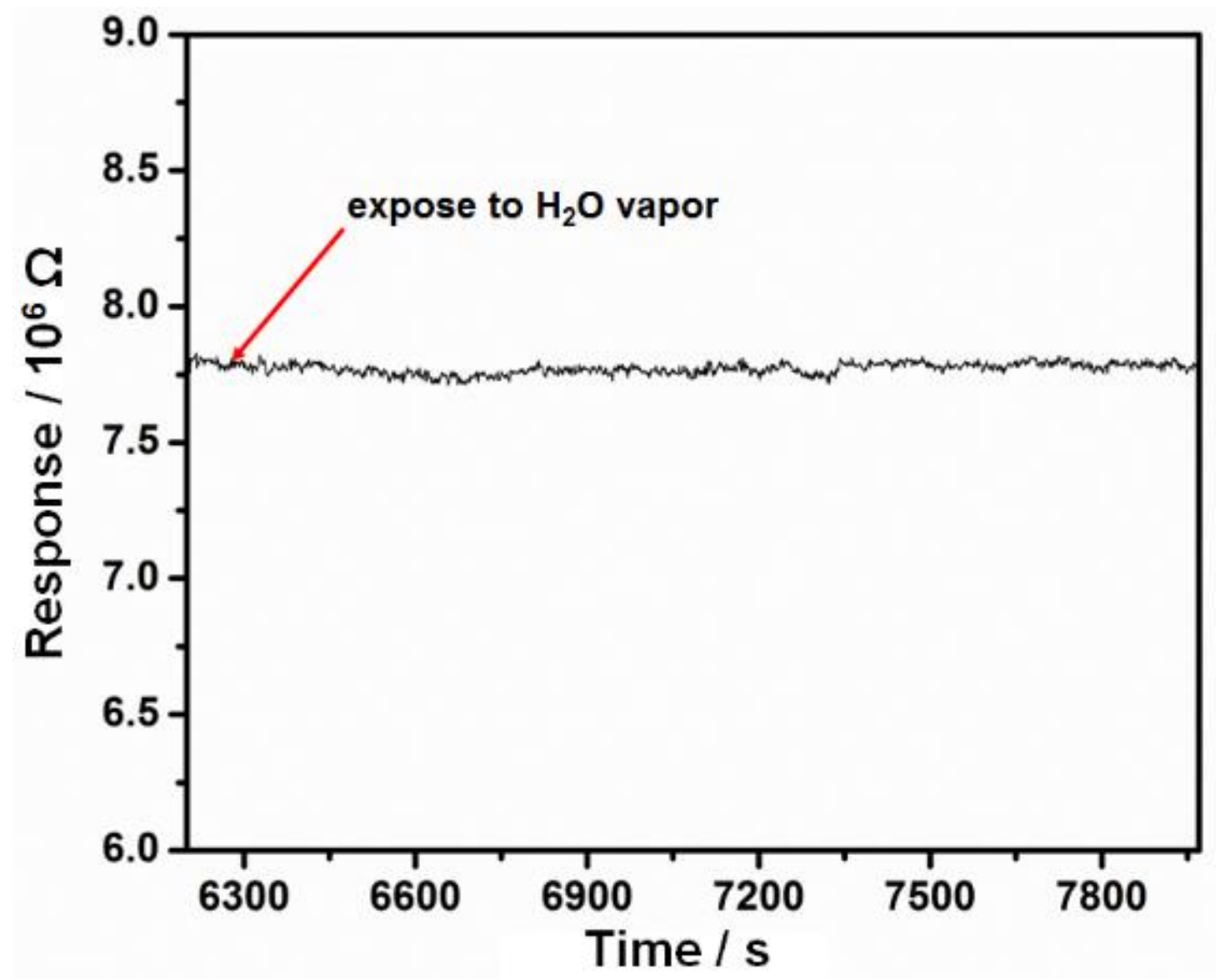

Figure S12. Sensing preformance of the large-pore mesoporous carbon carbon- $\mathrm{PEO}_{117}-b-\mathrm{PS}_{198}$ sensor to 1725 ppm water. 


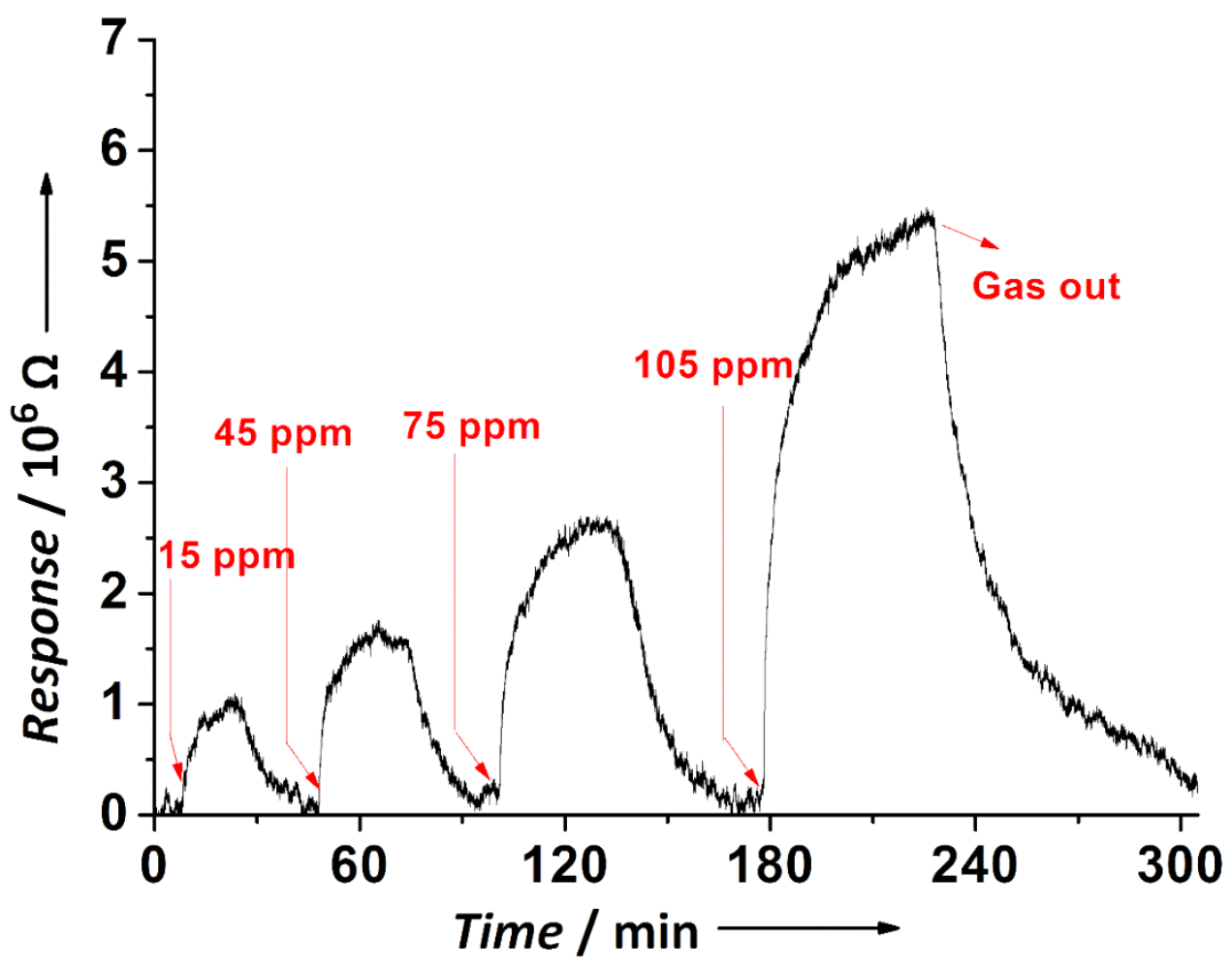

Figure S13. Response and recovery curves of the mesoporous carbon C-FDU-15 with 2D hexagonal mesostructure and a pore size of $3.3 \mathrm{~nm}$ to $\mathrm{NH}_{3}$ at different concentrations $(15-105 \mathrm{ppm})$ at room temperature. 


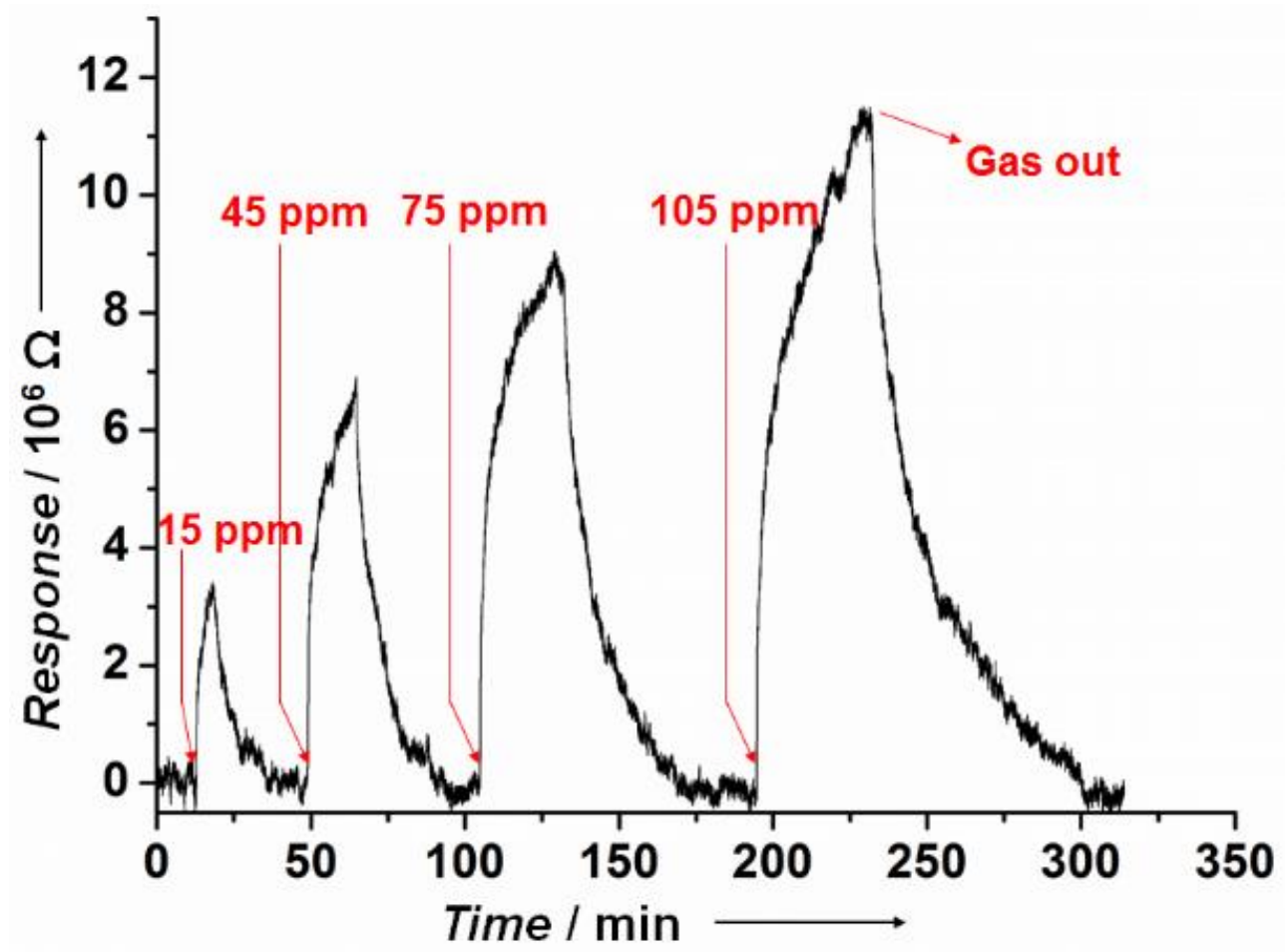

Figure S14. Response and recovery curves of the mesoporous carbon carbon- $\mathrm{PEO}_{117}-b-\mathrm{PS}_{97}$ with $2 \mathrm{D}$ hexagonal mesostructure and a pore size of $13.8 \mathrm{~nm}$ to $\mathrm{NH}_{3}$ at different concentrations $(15-105 \mathrm{ppm})$ at room temperature. 
Table S2. The absorption energy $\left(\mathrm{E}_{\mathrm{ab}}\right)$ of $\mathrm{NH}_{3}$ with pure tetragonal amorphous graphite, defect graphite surface, hydroxyl $(-\mathrm{OH})$, carboxyl $(-\mathrm{COOH})$ and ketone $(-\mathrm{C}=\mathrm{O})$.

\begin{tabular}{cccccc}
\hline & $\mathrm{NH}_{3} @$ graphite & $\mathrm{NH}_{3} @$ defect & $\mathrm{NH}_{3} @ \mathrm{CO}$ & $\mathrm{NH}_{3} @ \mathrm{OH}$ & $\mathrm{NH}_{3} @ \mathrm{COOH}$ \\
\hline $\begin{array}{c}\text { Absorption } \\
\text { Energy }\end{array}$ & 0.07 & 0.04 & 0.04 & 0.40 & 0.51 \\
\hline
\end{tabular}



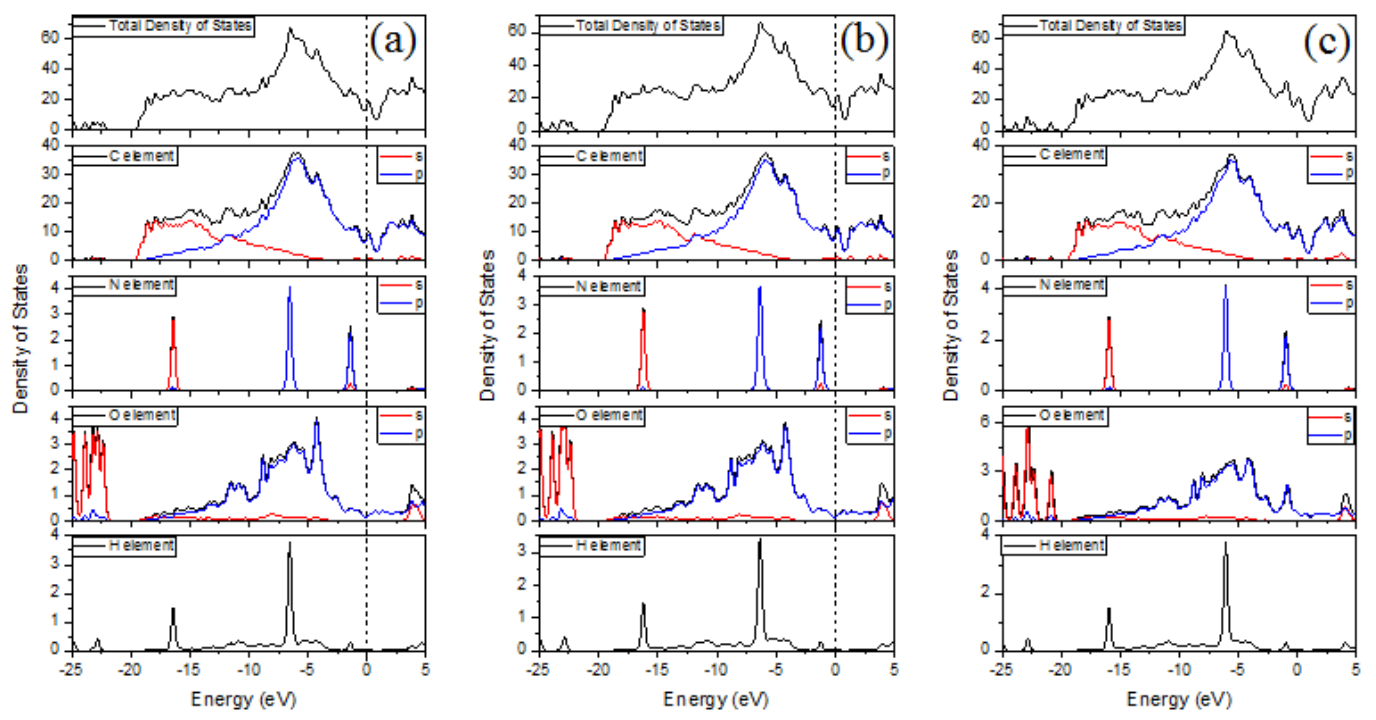

Figure S15. Calculated density of states of mesoporous carbon with (a) graphite-structured surface, (b) defected surface, (c) $-\mathrm{C}=\mathrm{O}$ at surface. The zero of energy is aligned with the top of the valence band. The red and blue lines represent the $\mathrm{s}$ and $\mathrm{p}$ orbitals of corresponding element. 

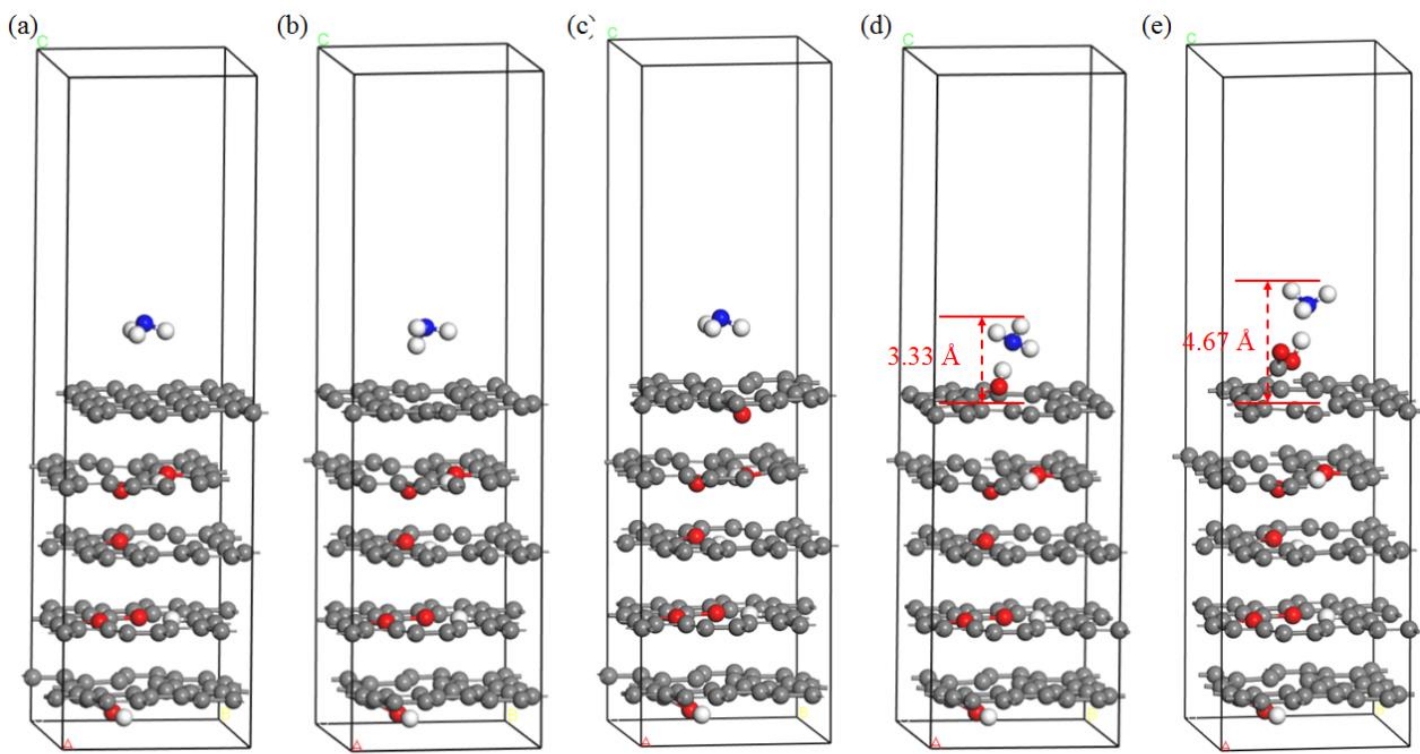

Figure S16. Calculated structures of $\mathrm{NH}_{3}$-absorbed mesoporous carbon with (a), graphite-structured surface; (b), defected surface; (c), - $\mathrm{CO}$ at surface; (d), -OH at surface; (e), - $\mathrm{COOH}$ at surface. In this calculation, because the neighboring ammonia molecules at the surface of the mesoporous carbon do not interact with each other in the simulation experiments, we employed tetragonal amorphous graphite ( $a=9.84, b$ $=8.52, c=30.40 \AA$ ) to theoretically investigate the ammonia molecules and our ordered mesoporous carbons (OMCs). The internal $-\mathrm{OH}$ and $-\mathrm{COOH}$ groups are confined in the graphitic layer, and no interaction exists between the adjacent graphitic layers because of the layered structure of graphite. As a result, the absorption of ammonia on OMCs mainly occurs on the surface with active sites. 


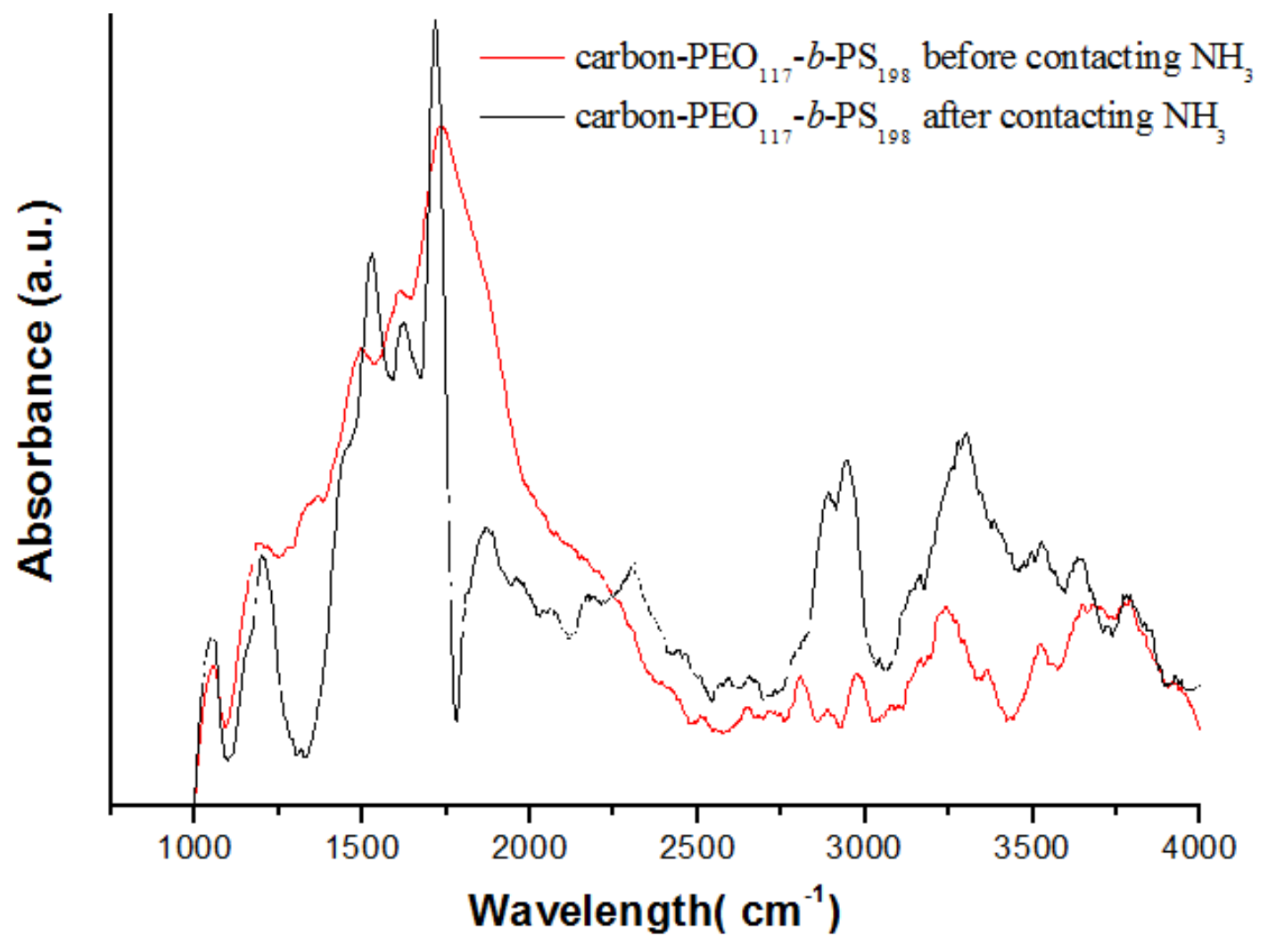

Figure S17. Fourier-transform infrared (FT-IR) spectra of the mesoporous carbon carbon- $\mathrm{PEO}_{117}-b-\mathrm{PS}_{198}$ before and after contacting with $100 \mathrm{ppm} \mathrm{NH}_{3}$ for $1 \mathrm{~min}$. The mesoporous carbon- $\mathrm{PEO}_{117}-b$ - $\mathrm{PS}_{198}$ materials show a strong absorption at around $1730 \mathrm{~cm}^{-1}$ attributed to $-\mathrm{COOH}$ groups. After exposure to $100 \mathrm{ppm} \mathrm{NH}_{3}$ for $1 \mathrm{~min}$, the band becomes broad and weakened possibly due to the formation of carboxylate, confirming the strong interaction between the $\mathrm{OMCs}$ and $\mathrm{NH}_{3}$ molecules. 